\title{
An Option for Good Outcome of Intracerebral Hematoma
}

\author{
AHMED ALI, M.D.* and HUSSEIN SOFFAR, M.D.** \\ The Department of Neurosurgery, Faculty of Medicine, Cairo** and Bani Suif* Universities
}

\begin{abstract}
Background: Intracerebral hematoma affects about 2.5 per 10,000 people each year. The incidence is more in males and older people. The mortality rate is about $44 \%$ in the first month. $20 \%$ of cases has a good outcome. Symptoms can include headache, one-sided weakness, vomiting, seizures, decreased level of consciousness, and neck stiffness. Often symptoms get worse over time. In many cases bleeding occurs in the brain tissue and the ventricles at the same time. Many procedures and techniques have been introduced for the management of intracerebral hematoma and debate always exist about the management of sizable intracerebral hematomas especially if the conscious level isn't markedly affected.
\end{abstract}

Aim of Study: To evaluate the role of early evacuation of sizable intracerebral hematomas even if the conscious level isn't markedly deteriorated.

Method: This is a retrospective study of 30 cases of intracerebral hematoma operated in Kasr El-Aini Hospitals and Bani Suef University Hospitals by evacuation assisted by microscope with a Glasgow Coma Scale more than 10 in most cases with a sizable intracerebral haemorrhage more than $30 \mathrm{cc}$ in the volume.

Results: This study results was $22(73 \%)$ male patients and $8(27 \%)$ was female patients. The age group was 4 patients $(13 \%)$ under 30 years, 22 patients $(73 \%)$ were from $30-45$ years and 4 patients (13\%) were more than 45 years old. The Glasgow Coma Scale (GCS) on admission was 14-15 in 4 patients $(13 \%)$ patients, from $10-13$ was 14 patients $(46 \%)$, and from 9 and less was 12 patients (41\%). 20 patients (67\%) case was diabetics, 23 patients $(46 \%)$ cases was hypertensive, 2 patients $(7 \%)$ had chronic renal failure on regular dialysis, 1 patient (3\%) case was pregnant. The GCS post-operative was $14-15$ in 20 patients (70\%), 10-13 in 5 patients (16\%), and from 9 and less in 5 (24\%) cases. The operation done was evacuation in all cases, decompressive craniectomy in 8 patients (26\%), ventriculosubgaleal shunt done (VSG) in 3 patients $(10 \%)$. The side of the hematoma was left sided in 7 patients $(24 \%)$, right in 23 patients $(76 \%)$. Good out come in 25 cases $(83 \%)$, recollection in $3(10 \%)$ cases, residual hematoma in $2(6 \%)$ of the cases, re evacuation done in 1 patient $(3 \%)$. Mortality were 4 patients.

Correspondence to: Dr. Ahmed Ali, The Department of Neurosurgery, Faculty of Medicine, Bani Suif University
Conclusion: Sizable intracerebral hematoma (volume more than 30cc) in good Glasgow coma scale mostly obeying orders, spontaneous eye opening, and aphasic or not, to obtain a good outcome is to evacuate the hematoma not to wait for conservative management.

Key Words: Intracerebral hematoma - The Glasgow coma scale (GCS).

\section{Introduction}

INTRACEREBRAL hematoma affects about 2.5 per 10,000 people each year. The incidence is more in males and older people. The mortality rate is about $44 \%$ in the first month. $20 \%$ of cases have a good outcome. Strokes are divided into two major types, ischemic (due to insufficient blood flow) and hemorrhagic (due to bleeding).

When due to high blood pressure, intracerebral hemorrhages typically occur in the putamen $(50 \%)$ or thalamus (15\%), cerebrum (10-20\%), cerebellum $(10-13 \%)$, pons $(7-15 \%)$, or elsewhere in the brainstem $(1-6 \%)$.

Symptoms can include headache, one-sided weakness, vomiting, seizures, decreased level of consciousness, and neck pain. Symptoms get worse over time. In many cases bleeding occurs in both the brain tissue and the ventricles.

Other causes for intracerbral hemorrhage include brain trauma, aneurysms, arteriovenous malformations, and brain tumors. High blood pressure and amyloidosis are the main risk factors for spontaneous bleeding. Other risk factors include alcoholism, high cholesterol, blood thinners, and cocaine use. Diagnosis is typically by CT scan. Ischemic stroke may have the same presentations.

Both Computed Tomography Angiography (CTA) and Magnetic Resonance Angiography 
(MRA) are commonly used to diagnose intracranial vascular malformations after $\mathrm{ICH}$.

Treatment may include both medication and surgery and it depends substantially on the type of ICH which is determined by Rapid CT scan and other diagnostic measures.

Tracheal intubation is indicated if the conscious level is markedly affected.

Treatment is better to be carried out in an Intensive Care Unit with recommendations to decrease the blood pressure to a systolic of 140 $\mathrm{mmHg}$. Blood sugar kept in the normal range. A ventricular drain may be used to treat hydrocephalus but corticosteroids are not recommended. Surgical evacuation of the hematoma is used in some cases.

\section{Patients and Methods}

This is a retrospective study of 30 cases of intracerebral hematoma operated in Kasr El-Aini Hospitals and Bani Suef University Hospitals (between January 2019 and January 2020) by evacuation assisted by microscope with a Glasgow
Coma Scale more than 10 in most cases with a sizable intracerebral hematoma more than $30 \mathrm{cc}$ in the volume.

Management: When the patient came to ER in the hospital neurosurgery doctor assess him and call for CT brain as soon as possible, then ICU admission, blood pressure assessed, full laboratory investigations and images done, if the CT showed sizable intracerebral hematoma, the patient was prepared for urgent surgery. The main role is to do intracerebral hematoma evacuation beside a large bone flap as a decompressive craniectomy to the patient, as it helps to decompress the brain (in some cases). Intracerebral hematoma evacuation to be done completely as much as possible, a good hemostasis must done. The patient dural closure by duroplasty by pericranium or fascia lata, the bone flap is fixed loose to decompress the brain. Good blood pressure control after surgery to prevent recollection of the hematoma. Follow-up CT brain was done immediately after surgery. Close observation of the patient by GCS.

The following items are assessed in the postoperative period: GCS, ICU period of stay, postoperative complications and the estimated cost.

Table (1): The master table.

\begin{tabular}{|c|c|c|c|c|c|c|c|c|c|}
\hline & Age & Sex & $\begin{array}{c}\text { GCS } \\
\text { admission }\end{array}$ & DM/HTN & $\begin{array}{l}\text { GCS } \\
\text { post }\end{array}$ & Operation & Deficits & F-up CT & $\begin{array}{c}\text { Side of } \\
\text { hematoma }\end{array}$ \\
\hline 1 & 45 & M & 13 & Yes & 15 & Evacuation & RT side G3 & Good & Left \\
\hline 2 & 55 & M & 8 & Yes & 14 & DECOP /EVC & Lt sided G0 & Good & Right \\
\hline 3 & 48 & $\mathrm{~F}$ & 12 & Yes & 15 & DECOMP/EVC & LT sided G0 & Good & Right \\
\hline 4 & 52 & M & 9 & Yes RF & 9 & DOMP/EVC & Rt Sides G0 & Residual & Left \\
\hline 5 & 38 & M & 13 & MVR & 15 & DECOP/EVC & LT G0 & Good & $\mathrm{RT}$ \\
\hline 6 & 27 & $\mathrm{~F}$ & 13 & H PREG & 15 & Evcuation & Lt sided G1 & Good & RT \\
\hline 7 & 55 & M & 13 & Yes & 15 & Evacuation & LT sided G2 & Good & Right \\
\hline 8 & 68 & $\mathrm{~F}$ & 9 & Yes & 9 & $\mathrm{EVC/DEC/VSG}$ & LT sided g1 & Good & Right \\
\hline 9 & 60 & $\mathrm{M}$ & 9 & Yes & 9 & EVC/DC/VSG & LT sided g2 & Good & RT \\
\hline 10 & 50 & M & 13 & Yes & 14 & EVC/DC & LT sided g2 & Good & RT \\
\hline 11 & 45 & M & 12 & Yes & 15 & EVC & LT G3 & Good & RT \\
\hline 12 & 50 & M & 14 & Yes & 10 & $\mathrm{EVC}$ & LT G2 & REC & RT \\
\hline 13 & 18 & $\mathrm{~F}$ & 13 & No & 15 & EVC & LT G3 & REC & RT \\
\hline 14 & 64 & M & 14 & Yes & 15 & EVC & RT G0 & Good & RT \\
\hline 15 & 70 & M & 9 & Yes & 7 & EVC & RT G0 & REC/R EV & LT \\
\hline 16 & 64 & $\mathrm{~F}$ & 9 & Yes & 12 & VSG & FMP & Good & No \\
\hline 17 & 75 & M & 10 & Yes & 12 & EVC & LT G0 & Good & RT \\
\hline 18 & 51 & M & 15 & No & 15 & EVC & NO & Good & RT \\
\hline 19 & 18 & M & 15 & No & 14 & EVC & NO & Good & RT \\
\hline 20 & 40 & $\mathrm{~F}$ & 12 & Yes & 15 & EVC & LT S HEAV & Good & RT \\
\hline 21 & 55 & M & 13 & Yes & 15 & EVC & LT & Good & RT \\
\hline 22 & 65 & M & 9 & Yes & 13 & EVC & LT & Good & RT \\
\hline 23 & 59 & M & 10 & Yes & 13 & EVC & $\mathrm{RT}$ & Good & LT \\
\hline 24 & 55 & $\mathrm{~F}$ & 8 & HTN & 9 & EVC & RT & Good & LT \\
\hline 25 & 67 & M & 12 & CR yes & 14 & EVC & RT & Good & LT \\
\hline 26 & 54 & M & 9 & HTN & 9 & EVC/DEC & LT & Good & LT \\
\hline 27 & 6 & M & 9 & No & 14 & EVC & NO & Good & RT \\
\hline 28 & 50 & $\mathrm{~F}$ & 9 & Yes & 9 & EVC & NO & RESI & ML \\
\hline 29 & 65 & M & 9 & Yes & 14 & EVC & LT & Good & RT \\
\hline 30 & 60 & M & 11 & Yes & 15 & EVC & LT & Good & RT \\
\hline
\end{tabular}




\section{Results}

This study results was $22(73 \%)$ male patients, $8(27 \%)$ was female patients. The age group was 4 patients (13\%) under 30 years, 22 patients (73\%) was from 30-45 years and 4 patients (13\%) was more than 45 years old. The Glasgow coma scale (GCS) on admission was $14-15$ in 4 patients $(13 \%)$ patients, from 10-13 in 14 patients (46\%) patients, and from 9 and less in 12 patients $(41 \%)$ cases. 20 patients $(67 \%)$ were diabetics, 23 patients $(46 \%)$ were hypertensive, 2 patients $(7 \%)$ had chronic renal failure on regular dialysis, 1 patient (3\%) was pregnant. The GCS post-operative was $14-15$ in $20(70 \%)$ cases, $10-13$ in $5(16 \%)$ cases, and from 9 and less in $5(24 \%)$ cases. The operation done was evacuation in all cases, decompressive craniotomy in 8 cases (26\%), ventriculosubgaleal done (VSG) in 3 cases $(10 \%)$. The side of the hematoma was left sided in 7 patients $(24 \%)$, right in 23 patients $(76 \%)$. Good out come in 25 cases $(83 \%)$, recollection in $3(10 \%)$ cases, residual hematoma in $2(6 \%)$ of the cases, re-evacuation was done in $1(3 \%)$ case. 4 cases died.

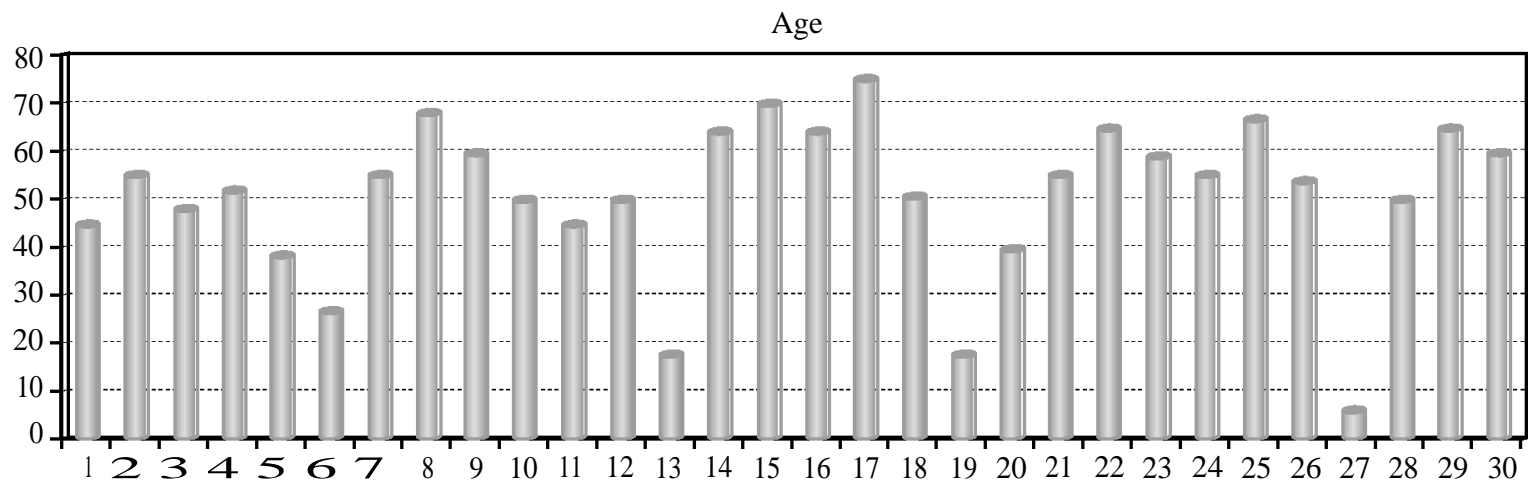

Fig. (1): The age.

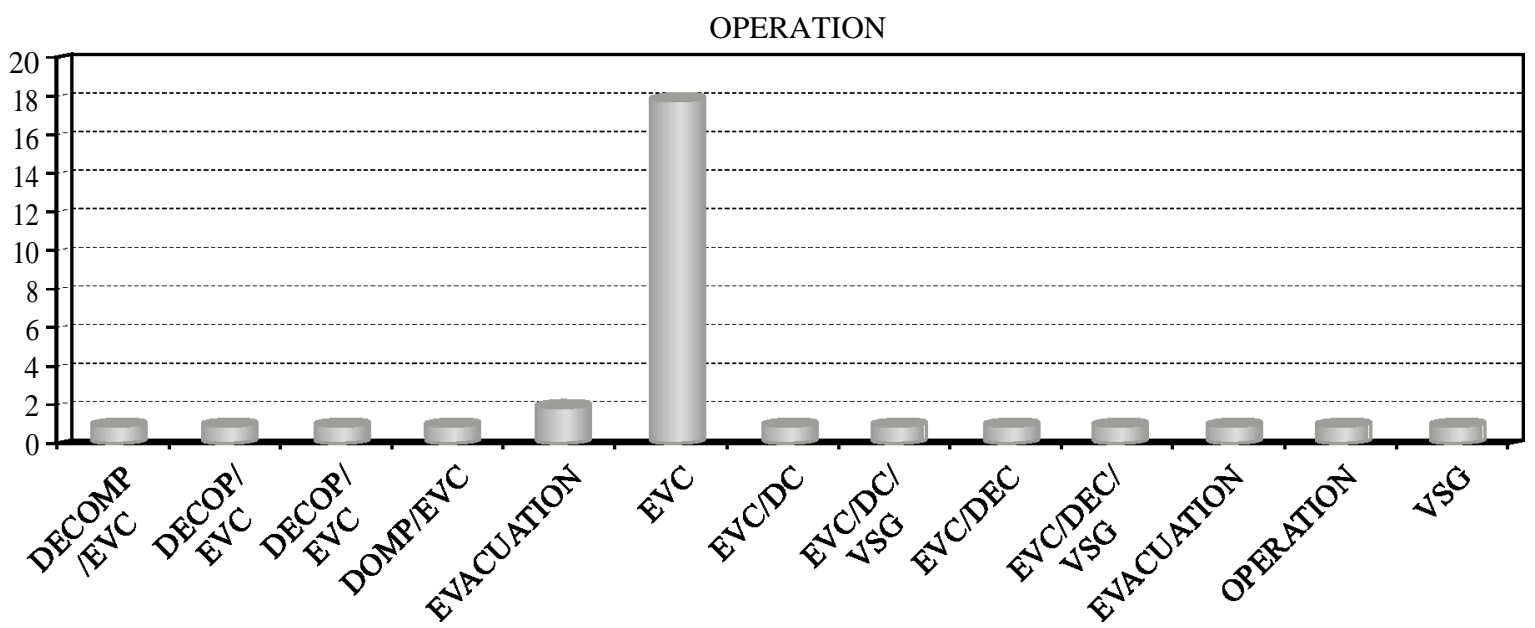

Fig. (2): The operations done.

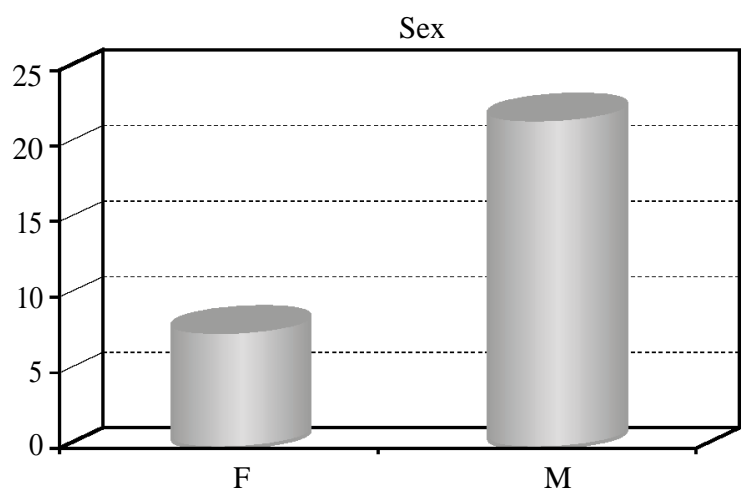

Fig. (3): The sex.

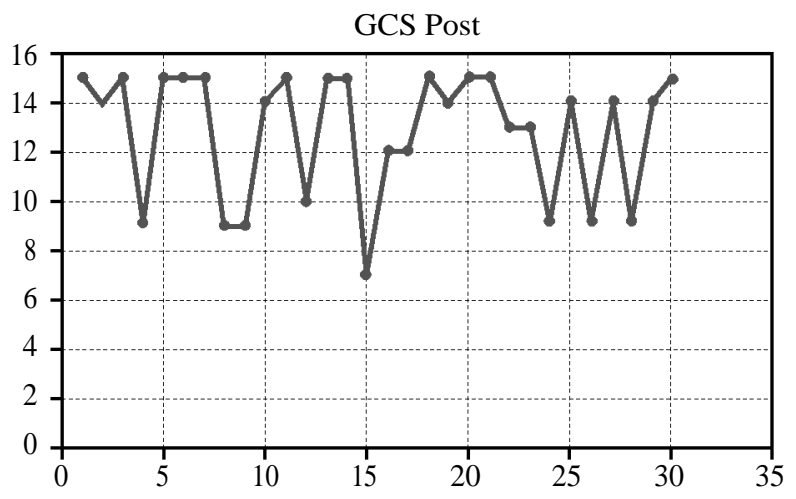

Fig. (4): Post-operative GCS. 

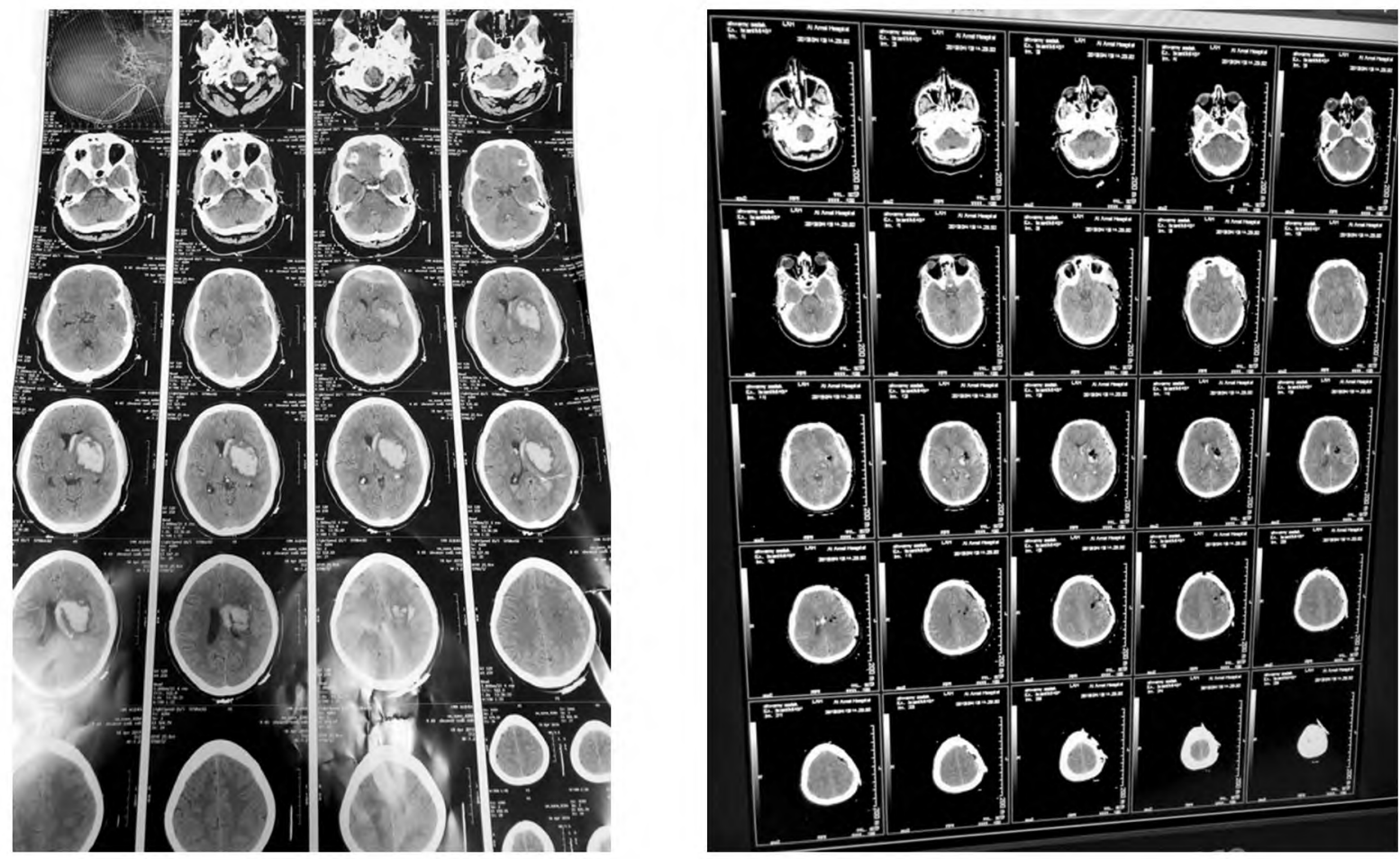

Fig. (5): Pre-operative CT scan post-operative CT scan.
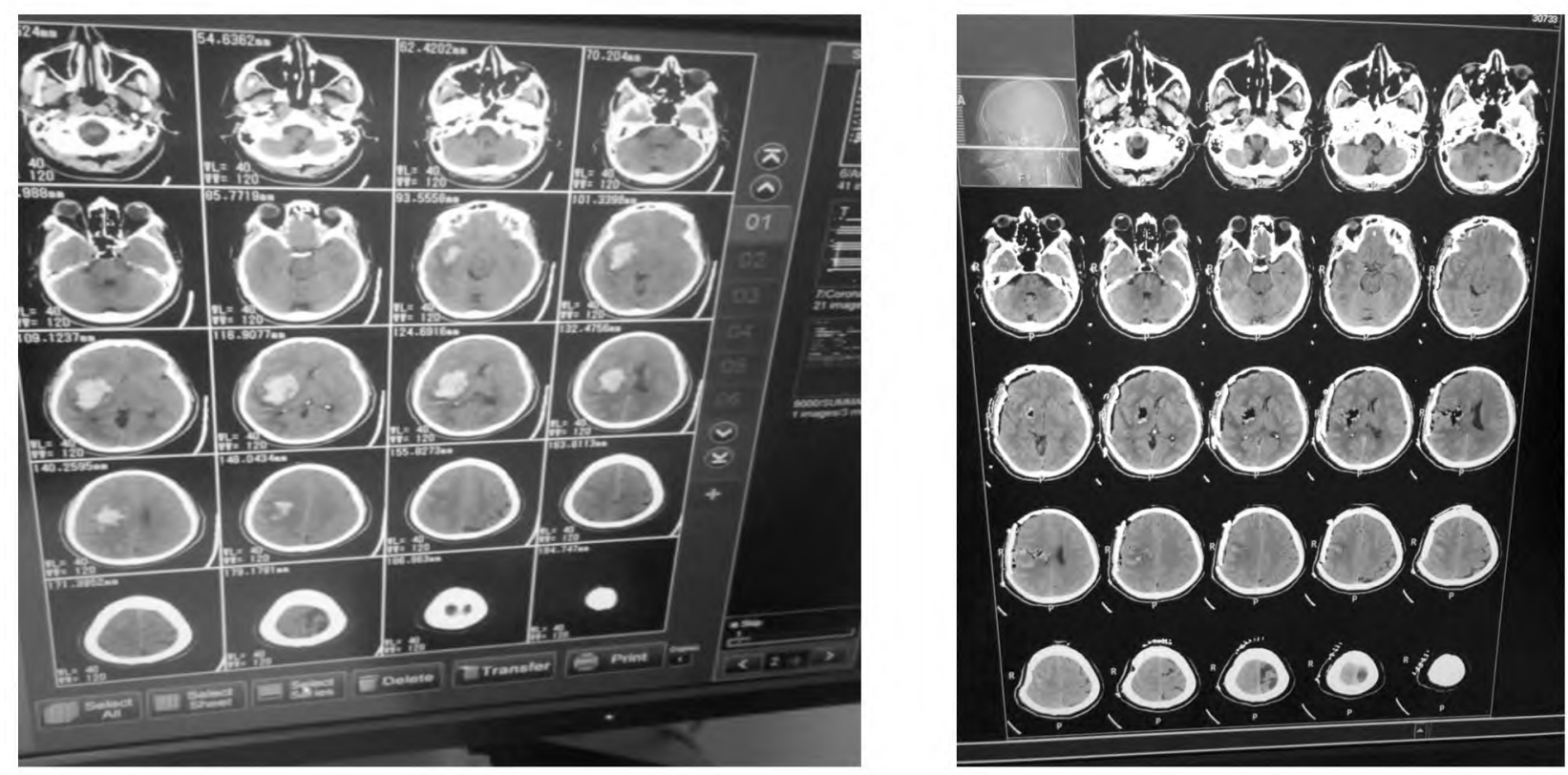

Fig. (6): Pre-operative CT scan post-operative CT scan. 

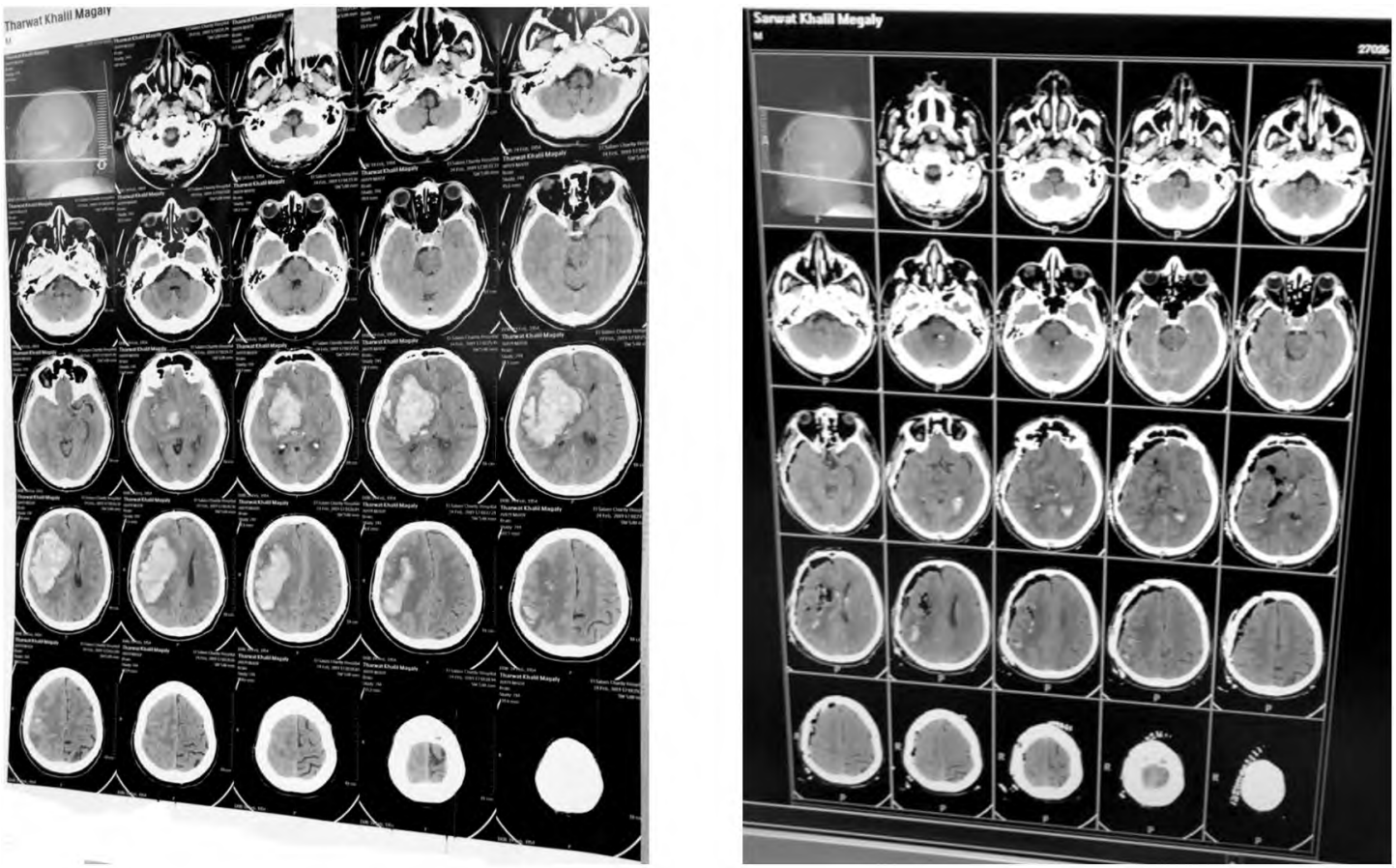

Fig. (7): Pre-operative CT scan post-operative CT scan.
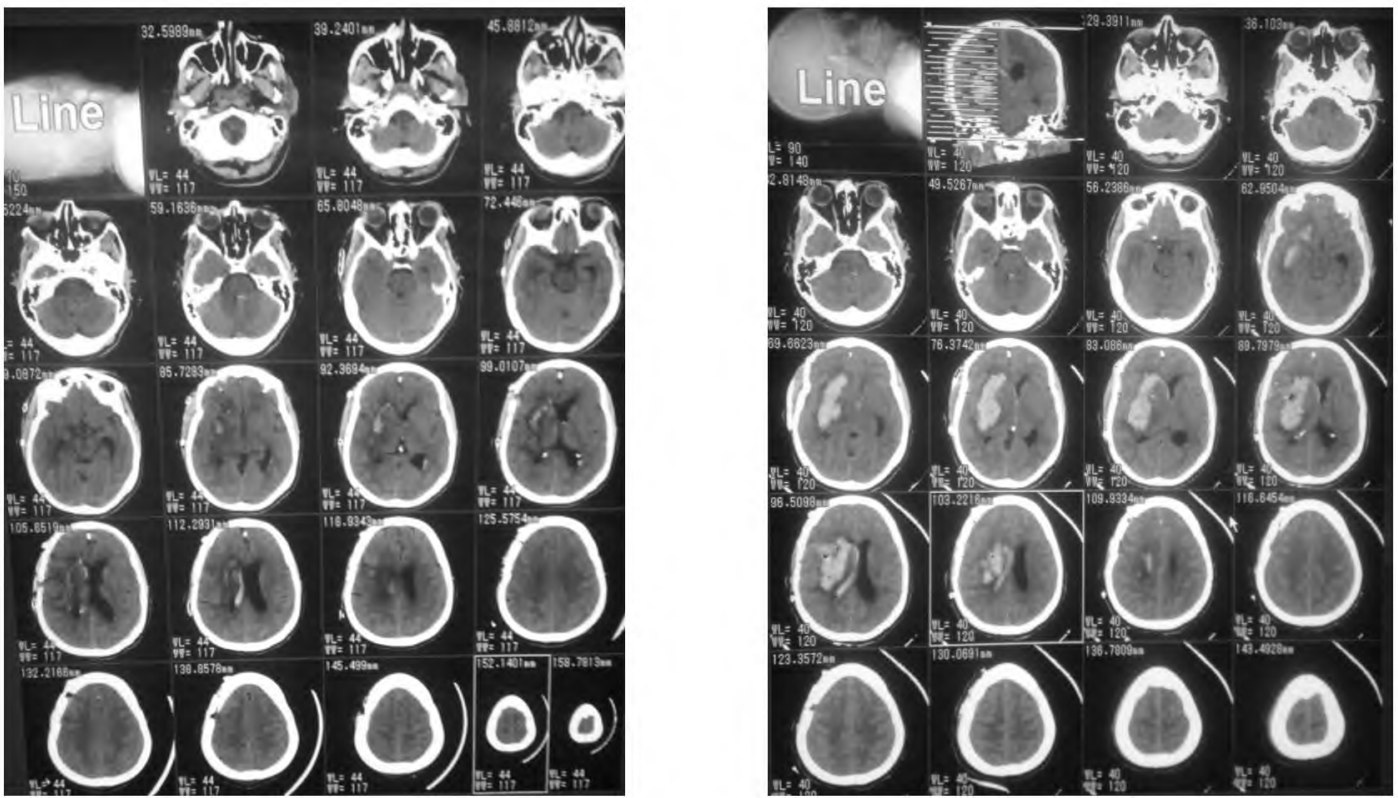

Fig. (8): Pre-operative and post-operative CT SCAN.

\section{Discussion}

In this study we discuss the surgical management of intracerebral hematoma, especially in patients with a good GCS as soon as early as possible post appearance of the symptoms, and if it helps to obtain good results, as ICH (intracerebral hemorrhage) is a neurosurgical emergency. The patient is managed as a whole, GCS on admission, morbid diseases as diabetes, hypertension, cardiac, renal diseases, or he had a disease else not control- led. The main risk factor is high blood pressure and diabetes this with Alshahi Salman, et al. [1] The site of the hematoma mainly basal ganglia this is with Hemphill, et al. [6], the main complaint was disturbed conscious level in our series of 30 patients only 2 patients came early with headache, nausea and vomiting this against Niadich, et al. [10], for spontaneous ICH seen on CT scan, the death rate (mortality) is $34-50 \%$ by 30 days after the insult Lan, et al. [8], this is against our study in which mortality rate were $14 \%$. Intraparenchymal bleeds 
within the medulla oblongata are fatal in almost all case, because they cause damage to cranial nerve $\mathrm{X}$, the vagus nerve, which plays an important role in blood circulation and + breathing, Boulouis, et al. [2]. We had no cases reported in the brain stem all case cortical and subcortical, we discuss in our study if the surgical option in intracerebral hematoma treatment is important for these patients who have sizable hematoma more than 30cc blood in its volume in good Glasgow coma scale more than 9 especially in young age, hypertensive emergency.

Whatever posterior fossa, cerebral cortex and basal ganglia hematoma we must evacuate as soon as hematoma sizable and the Glasgow Coma Scale (GCS) good option for surgery give good results. Endoscopic drainage or Aspiration by stereotactic surgery may be used in basal ganglia hemorrhages, although successful reports are limited Caceres JA, et al. [3], this is against our operative technique which was microscopic evacuation and/or decompressive craniectomy without use of endoscope or stereotactic aspiration.

\section{Conclusion:}

Sizable intracerebral haemorrhage (volume more than 30cc) in good Glasgow Coma Scale mostly obeying orders, spontaneous eye opening, and aphasic or not, to obtain a good outcome (short ICU stay, bed ridden \& the cost) is to evacuate the hematoma not to wait for conservative medical treatment also decrease mortality as many cases has a rapid drop of the GCS to a level the surgery has no role, if we depend on that GCS is good and we wait not to operate as many patients may die.

\section{References}

1- AL-SHAHI SALMAN R., LAW Z.K., BATH P.M., STEINER T. and SPRIGG N.: (17 April 2018). "Haemostatic therapies for acute spontaneous intracerebral haemorrhage". The Cochrane Database of Systematic Reviews. 4: CD005951. doi:10.1002/14651858.CD005951.pub4. PMID 29664991, 2018.

2- BOULOUIS GREGOIRE, MOROTTI ANDREA, GOLDSTEIN JOSHUA N. and CHARIDIMOU ANDREAS: (1 April 2017). Intensive blood pressure lowering in patients with acute intracerebral haemorrhage: Clinical outcomes and haemorrhage expansion. Systematic review and metaanalysis of randomised trials". Journal of Neurology, Neurosurgery, and Psychiatry, 88 (4): 339-45. doi: 10.1136/jnnp-2016-315346. ISSN 1468-330X. PMID 28214798.

3- CACERES J.A. and GOLDSTEIN J.N.: (August 2012). "Intracranial hemorrhage". Emergency Medicine Clinics of North America, 30 (3): 771-94, doi: 10.1016/j.emc.2012. 06.003. PMC 3443867. PMID 22974648, 2012.
4- FELDMANN EDWARD, BRODERICK JOSEPH P., KERNAN WALTER N., VISCOLI CATHERINE M., BRASS LAWRENCE M., BROTT THOMAS, MORGENSTERN LEWIS B., LEE WILTERDINK JANET and HORWITZ RALPH I.: "Major Risk Factors for Intracerebral Hamorrhage in the Young Are Modifiable". Stroke. 36 (9): 1881-5. doi: 10.1161/01.str.0000177480.62341.6b. PMID 16081867. Archived from the original on 200903-05, 2005.

5- GREENBERG MARK S.: Handbook of Neurosurgery. ISBN 9781626232419. Prayson, Richard A. (2012). Neuropathology. Elsevier Health Sciences. p. 49. ISBN 9781437709490. Archived from the original on 2017-03-12, 2016.

6- HEMPHILL J.C. 3 rd, GREENBERG S.M., ANDERSON C.S., BECKER K., BENDOK B.R., CUSHMAN M., FUNG G.L., GOLDSTEIN J.N., MACDONALD R.L., MITCHELL P.H., SCOTT P.A., SELIM M.H. and WOO D.: American Heart Association Stroke, Council; Council on Cardiovascular and Stroke, Nursing; Council on Clinical, Cardiology (July 2015). "Guidelines for the Management of Spontaneous Intracerebral Hemorrhage: A Guideline for Healthcare Professionals From the American Heart Association/American Stroke Association". Stroke: A Journal of Cerebral Circulation. 46 (7): 2032-60. doi: 10.1161/str.0000000000000069. PMC 4462131. PMID 26022637, 2015.

7- JOSEPHSON COLIN B., WHITE PHILIP M., KRISHAN ASHMA and AL-SHAHI SALMAN: Rustum (1 September 2014). "Computed tomography angiography or magnetic resonance angiography for detection of intracranial vascular malformations in patients with intracerebral haemorrhage". The Cochrane Library. 9 (9): CD009372. doi:10.1002/14651858.CD009372.pub2. PMID 25177839, 2014.

8- LAN X., HAN X., LI Q., YANG Q.W. and WANG J.: "Modulators of microglial activation and polarization after intracerebral haemorrhage". Nat. Rev. Neurol., 13 (7): 420-33. doi:10.1038/nrneurol.2017.69. PMC 5575938. PMID 28524175, 2017.

9- McCAFFREY P.: "The Neuroscience on the Web Series: CMSD 336 Neuropathologies of Language and Cognition." Archived 2005-11-25 at the Wayback Machine California State University, Chico. Retrieved on June 19, 2007, 2001. Orlando Regional Healthcare, Education and Development: "Overview of Adult Traumatic Brain Injuries." Archived 2008-02-27 at the Wayback Machine Retrieved on 2008-01-16, 2004.

10- NAIDICH THOMAS P., CASTILLO MAURICIO, CHA SOONMEE and SMIRNIOTOPOULOS JAMES G.: Imaging of the Brain, Expert Radiology Series, 1: Imaging of the Brain. Elsevier Health Sciences. p. 387. ISBN 9781416050094. Archived from the original on 2016-10-02, 2012.

11- SHEPHERD S.: "Head Trauma." Archived 2005-10-26 at the Wayback Machine Emedicine.com. Retrieved on June 19, 2007, 2004.

12- VINAS F.C. and PILITSIS J.: "Penetrating Head Trauma." Archived 2005-09-13 at the Wayback Machine Emedicine.com, 2014.

13- YADAV Y.R., MUKERJI G., SHENOY R., BASOOR A., JAIN G. and NELSON A.: "Endoscopic management of 
hypertensive intraventricular haemorrhage with obstructive hydrocephalus". BMC Neurol., 7: 1. doi: 10.1186/14712377-7-1. PMC 1780056. PMID 17204141. Archived from the original on 2008-06-05, 2007. Go AS, Mozaffarian D, Roger VL, et al. (January 2013). "Heart disease and stroke statistics--2013 update: A report from the American Heart Association". Circulation. 127 (1): e6- e245. doi: 10.1161/CIR.0b013e31828124ad. PMC 5408511. PMID 23239837, 2013

14- YEUNG R., AHMAD T., AVIV R.I., NOEL De TILLY L., FOX A.J. and SYMONS S.P.: "Comparison of CTA to DSA in determining the etiology of spontaneous ICH". Canadian Journal of Neurological Sciences, 36 (2): 17680. doi: 10.1017/s0317167100006533, 2009.

\section{لتحسين النتائج فى النزيف داخل آنسجة المخ إختيار}

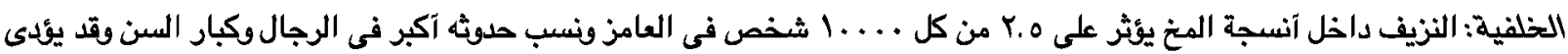

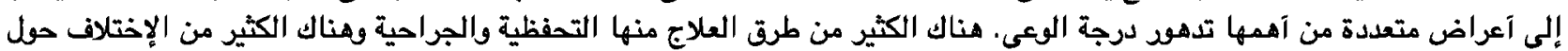

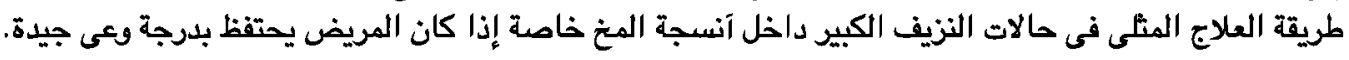
الهدف: معرفة تآثير العلاج الجراحى عن طريق تفريغ النزيف وخاصة فى الحالات التى تعانى من نزيف كبير الحجم داخل آنسجة المخ ودرجة وعى جيدة.

الطريقة: تم تجميع المعلومات من · r حالة تم إجراء جراحة لتفريغ النزيف داخل آنسجة المخ ودراسة نتائج ما بعد إجراء الجراحة متضمنة درجة الوعى ومدة الإقامة في الرعاية المركزة والمضاعفات المحتملة.

$$
\text { النتائج: آثتبت النتائج آن إجراء الجراحة بطريقة فعالة وبصورة عاجلة آدى إلى تصسن النتائج فى معظم المرضى. }
$$

الخلاصة: إجراء الجراحة التفريغ النزيف كبير الحجم (آكثر من •اسم) يؤدى إلى تحسن النتائج وسرعة شفاء المرضى. 